\title{
OBSERVATIONS
}

\author{
ON THE
}

\section{RELAXED REC'TUM,}

By THOMAS CHEVALIER, Esq. F.R.S. \& F.L.S.

SURGEON EXTRAORDINARY TO THE PRINCE REGENT, AND

CONSULTING SURGEON TO THE WESTMINSTER GENERAL DISPENSARY.

Reud Nov. 23, 1819.

A RELAXED state of the coats of the intestinal canal, admitting of excessive distension, is not of unfrequent occurrence. In most cases of peritoneal inflammation, whether acute or chronic, it is one of the earliest symptoms which arises, and affords a remarkable illustration of the pathological fact, that an inflammatory excess of action in the vessels of a part, is always accompanied with a loss of its tone. In this instance the inflammation is aggravated by the distension, and that distension rapidly increases in consequence of the adhesions which form between the convolutions of the intestines, and which, by arresting their peristaltic motion, tend greatly to disable them from expelling their contents. 
Parts of the canal, however, may become relaxed, and over distended in consequence of that relaxation, with little or no inflammation, and probably arising from a loss of tone simply. The large intestines seem more subject to this derangement than the small ones, and the transverse arch of the colon is especially liable to it. The extreme distension of the abdomen in tympanites is chiefly produced by the extraordinary degree in which this part is dilated. A less degree frequently accompanies ascites, and sometimes occasions an apprehension in the mind of the physician that there is a much larger quantity of fluid in the abdomen than is actually accumulated. In such instances, the fluctuation is more obscurely perceived, and it is chiefly at the lower part of the abdomen : the enlargement is greater above the navel than below it, and when the upper part of the belly is struck gently by the hand, it gives that peculiar sensation and sound which a membranous cavity filled with air communicates. This circumstance deserves the most careful attention on the part of the surgeon, who might otherwise be induced to tap the patient, and might puncture the intestines by his trocar. I believe, however, where this state of the colon exists, that the ascites is very seldom the principal disease. I have repeatedly objected to operate in such cases, having always found in those which I have had an opportunity of examining after death, that the quantity of fluid has been much less than had 
been expected, and that it has been irregularly effused among partial adhesions, which have been excited by the irritation of some visceral disease. If it should be thought adviseable in such a case to puncture the abdomen, the operation should be performed by the cautious introduction of a lancet through the linea alba below the navel, and not by a trocar.

Dilatations occasionally take place on the sigmoid flexure of the colon, the sacculated subdivisions of which prevent their dilated portions from being equally distended. From this cause scybala are often formed of the excrementitious matter, and may be retained for a considerable time by the valvular projections of its internal coat, although a tolerably regular evacuation of fæces may go on. These are well known to give rise to dysenteric affections, and inflammations of the inner surface of the bowel, in relieving many of which, copious and repeated glysters are of the most essential service, by softening and washing out the hardened substance.

That the lower part of the rectum is frequently so relaxed as to prolapse externally, is well known ; but it does not appear to have been much observed by practitioners that it is also subject, without any external protrusion whatever, to excessive dilatation within the pelvis, and to a semiprolapsus of its upper part into the lower. But this is a state 
of that bowel which frequently occurs. It is often productive of very distressing symptoms, and it is especially to be remarked, that it is a common cause of that obstinate and habitual costiveness, $s_{2}$, under which some persons continually labour.

The rectum commences from the colon, close to the last vertebræ of the loins, and passing down into the hollow of the sacrum, it takes the curvature of that bone, in which it lies comparatively loose, invested anteriorly, but not posteriorly, by the peritoneum. When it reaches the os coccygis, it quits the peritoneum entirely, and is connected loosely by cellular membrane to the bladder, to the muscles of the perineum, to the levatores ani, the sphincter ani, and the common integument. This lower portion of the rectum is easily distensible; but while it is in a natural state, the peculiar sensibility of its internal surface speedily excites it, - when moderately distended, unless the fæces are unnaturally hard, to expel its contents, and its muscular fibres are competent to enable it to do so, with a very moderate assistance from the action of the abdominal muscles. It is needless to say of how much consequence it is to the general health that the sensibilities of this important organ should remain unimpaired, and that strict attention should be paid to the regular performance of its functions : if this be long neglected, its natural sensibility becomes gradually diminished; it will 
remain overcharged for an undue time ; the energy of its muscular fibres will become impaired, so that a more forcible exertion of the abdominal muscles will be required to expel the stools, and not unfrequently this will also be insufficient, without some medicine be taken to quicken the action of the whole intestinal canal.

Here perhaps in a majority of cases, the evil stops. The calls of nature must be obeyed, and therefore persons who feel a difficulty in discharging the excretions regularly, are of necessity excited to employ those means which afford them the requisite assistance.

But in some instances, and these by no means rare, the lower part of the rectum becomes so frequently overloaded, and its irritability in consequence so much diminished, that it becomes excessively dilated, and almost loses the power of contracting upon its contents; the natural consent between that and its upper portion, which is covered by the peritoneum, and remains undilated, is thus weakened and further evil is induced. The superior portion of the rectum and the lower part of the colon, become also overloaded, and the deficiency in the action of these parts calling forth a greater exertion of the abdominal muscles, in the expulsion of the fæces, the upper, undilated portion of the rectum, is forced downwards into the lower and dilated portion, where it may be diso 
tïnctly felt like a loose bag, of which it is sometimes difficult to detect the aperture; the finger or a bougie being more likely to get entangled at the rim of this elongated fold, than to pass exactly into the continuation of the tube.

It is under these circumstances that the chief evils and perplexities of such cases begin. For the harmony of action between the upper and lower portions of the rectum being destroyed, the stools instead of being voided with that ease, and in that regular form and mass which is usual in a healthy state of the parts, are expelled with difficulty, in small and irregularly shaped pieces. The repeated efforts made for this purpose sometimes excite tenesmus, swelling of the hæmorrhoidal veins, and an increased secretion of mucus from the inner surface of the intestine; in men, the irritation is often communicated to the prostate gland, and neck of the bladder. In other instances, and especially in females, thepartsbecome so relaxed as to allow of a sufficient accumulation of fæces to fill the whole pelvis; and how unconscious a patient may be of such an accumulation; the following case, to which others might be added, will sufficiently shew.

A lady who was afflicted with cancer of the left breast, became affected with severe pain in the loins, which confined her to bed. She soon afterwards became unable to pass her urine, which was drawn off at proper intervals by a catheter. The vol. $x$. 
state of her bowels was regularly inquired into, and she always replied, that the evacuations were small in quantity, but frequent, and upon the whole, sufficient; and that this had been her ordinary habit for many years. After about a fortnight had elapsed in this way, her attendants noticed a peculiar appearance about the anus, which, on examination, was found dilated to the size of an half crown, by the protrusion of fæces, which had so stuffed the rectum, as completely to choke up the pelvis, and although not hardened, were incapable, from their quantity, of being removed without the assistance of instruments.

Sometimes hardened fæces accumulate in a similar manner, and become, from their bulk, incapable of expulsion without artificial aid, and yet that which is softer may pass over this lump in daily evacuations, and thus conceal the real mischief.

In more confirmed cases of the disease, and in persons of a sedentary habit, other bad consequences arise. The upper portion of the rectum being forced down as has been described, by a half intus-susception upon the lower, becomes in time less competent to its own functions, and transmits the fæces irregularly. The lower portion of the colon participates in this difficulty, and is kept in a state of irritation. An obscure heavy pain is felt in the lower part of the loins and the region of the sacrum; and the difficulty and imperfection 
MIX. CHEVALIEE ON RELAXED RECTUM. 407

with which the stools are voided, often gives rise to a suspicion that there is a stricture formed in some part of the intestinal tube; and this suspicion, although entirely groundless, will be confirmed in the apprehension both of the patient and his attendant, if, on making an examination with a bougie, its point should be arrested, as it is very likely to be, in the edge or fold of the semiprolapsed portion of the gut.

Under these circumstances, an increased secretion of mucus from the surface of the colon may take place, to a considerable amount, so as to collect in some of its sacculated portions, and to be voided in a large quantity; and as it then has often a yellowish appearance, it seems as if an abscess had burst, and its contents had been discharged by the anus. But the matter is more tenacious than true pus; it is not mixed with blood; that degree of relief and change from former feelings, which is always felt when an abscess breaks, is not experienced; the discharge does not go on regularly ; it is seldom seen above twice or thrice, and then this symptom disappears. I have several times known more than half a pint of this purulent looking mucus so voided, and then there has been no more for several days, or but once, and in some instances it has not recurred at all. A circumstance of this nature is sure to attract the patient's attention, and if mild and demulcent aperients are given, and temporary symptoms properly treated, 
all goes off : and the patient becoming more vigilant over the state of his bowels than formerly, the parts affected may greatly recover their health and tone, and he may be better than he had been for a considerable time before this occurrence took place.

The state of the rectum I have now been describing, is most common to females, and to persons who, from their habits being generally sedentary, are more apt to overlook the irregularities of its action, and to defer obedience to the calls of nature. Under these circumstances, purgative medicines are mostly resorted to, and the whole intestinal canal is teased and pained, for the defective action of that very part of it which is most remote from their influence. The general health also often suffers ; all the evils arising from costiveness taking place, and hypochondriacal dejection and gloom oppressing the mind.

In cases of this kind, the principal and most certain relief is to be obtained from the proper employment of glysters, the composition of which is to be regulated by circumstances. At first those of a mild aperient nature should be preferred, and thrown up by a syringe; and these should be repeated after regular intervals, so as to re-accustom the rectum to empty itself in an habitual way. Gruel, the decoction of mallows, broth, or milk with some honey, will answer the purpose very 
well ; but more permanent good will bè derived by using afterwards the infusion of chamomile, or the old decoction pro fotu, which by gently stimulating the torpid surface of the bowel, may bring on a proper contraction of its coats. Where the very lowest part of the rectum continues so dilated as to allow the upper still to descend, from four to six ounces of a strong decoction of oak bark, or an infusion of galls, thrown up as gently as possible every night, will be attended with the most beneficial effects. If this be not readily retained, a little starch, or a few drops of tincture of opium, or both, may be added to it ; and care should be taken at the same time so to regulate the diet, and medical treatment, that the upper part of the intestinal tube may be excited to due action, regularly, but not violently.

Should inflammation take place, which sometimes happens, at the prolapsed part, so as to consolidate the surfaces together, a permanent stricture or obstruction is formed, which, by the frequent irritation to which it must be unavoidably exposed, may take on a cancerous character, and be productive of the most disastrous effects. 